\title{
SISTEM INFORMASI AGENDA RAPAT BERBASIS WEB MENGGUNAKAN SMS GATEWAY (Studi kasus Polteknik TEDC Bandung)
}

\author{
Aris H. Rismayana ${ }^{1}$, Vivi Apriliani Nur² \\ ${ }^{1,2)}$ Program Studi Teknik Informatika \\ E-mail: rismayana@poltektedc.ac.id ${ }^{1}, \underline{\text { dest vhyvie@yahoo.com }}^{2}$
}

\begin{abstract}
Abstrak
Manajemen rapat adalah merencanakan, mengorganisasikan, memimpin, dan mengontrol rapat yang merupakan suatu kegiatan tatap muka resmi yang telah diagendakan yang dilakukan oleh dua orang atau lebih yang bertujuan untuk membahas suatu permasalahan, mencari jalan keluarnya dan mengambil keputusannya agar mencapai tujuan individu atau organisasi. Selama ini proses pembuatan agenda rapat di Politeknik TEDC Bandung masih dilakukan dengan cara manual, yaitu dengan membagikan surat atau undangan kepada yang bersangkutan atau mendatangi karyawan, begitu pula dengan informasi-informasi yang lainnya, sehingga memakan waktu dan sangat tidak efektif. Pada penulisan ilmiah yang berjudul Sistem Informasi Agenda Rapat ini, penulis mencoba membuat aplikasi yang dapat membantu proses pembuatan agenda rapat, serta mempermudah staf bagian kepegawaian untuk proses pembuatan informasi agenda rapat. Dengan memanfaatkan teknologi web dan SMS Gateway yang diterapkan pada sistem ini, dapat mempermudah kinerja staf dari kepegawaian dalam menyampaikan informasi via SMS kepada dosen atau karyawan di Politeknik TEDC Bandung, serta data-data yang dihasilkan lebih akurat, efektifitas waktu tanpa harus menyebar undangan ke setiap peserta rapat dan lebih hemat biaya. Sistem ini dirancang menggunakan diagram UML, serta untuk aplikasinya penulis menggunakan codeigniter yang merupakan framework PHP, serta MySQL sebagai tempat penyimpanan data. Akhir penulis berharap dengan adanya Sistem Informasi Agenda Rapat pada Politeknik TEDC Bandung dapat meningkatkan efisiensi kerja dan memaksimalkan pelayanan dalam pembuatan agenda rapat.
\end{abstract}

Kata kunci : Sistem Informasi, Manajemen Rapat, Codeigniter, MySQL, UML, SMS Gateway

\section{Pendahuluan}

Manajemen rapat adalah merencanakan, mengorganisasikan, memimpin, dan mengontrol rapat yang merupakan suatu kegiatan tatap muka resmi yang telah diagendakan yang dilakukan oleh dua orang atau lebih yang bertujuan untuk membahas suatu permasalahan, mencari jalan keluarnya dan mengambil keputusannya agar mencapai tujuan individu atau organisasi ${ }^{[1]}$.

Politeknik TEDC Bandung merupakan perguruan Tinggi yang memberikan pelayanan pendidikan dan telah memanfaatkan teknologi informatika, tetapi terdapat permasalahan, yaitu dalam pengolahan informasi agenda rapat masih secara manual dengan membagikan surat atau undangan kepada yang bersangkutan atau mendatangi karyawan, begitu pula dengan informasi-informasi yang lainnya. Selain itu pencatatan notula dan absensi rapat masih di lakukan dengan cara manual yaitu dengan menuliskan notula dan absensi diselembaran kertas dan kemudian mengetikan kembali ke komputer, hal ini menjadi tidak efisien dari segi waktu dan pemborosan kertas. Dengan berkembangnya cara berkomunikasi maka hal ini akan berpengaruh terhadap penyampaian informasi yang dilakukan setiap hari. Pada saat ini bukan tidak mungkin untuk menyampaikan informasi dengan jarak yang jauh, karena didukung dengan berkembangnya alat komunikasi tersebut. Dengan perkembangan teknologi informasi khususnya SMS maka penyampaian informasi dari jarak jauh akan bisa tersampaikan dengan cepat. SMS (Short Message 
Service) atau layanan pesan singkat, merupakan sebuah layanan yang diaplikasikan pada sistem komunikasi tanpa kabel, dengan pengiriman pesan dalam bentuk teks. SMS didukung oleh teknologi GSM (Global System For Mobile Communication), TDMA (Time Division Multiple Access), CDMA (Code Division Multiple Access) yang berbasis pada telepon seluler dan saat ini masih banyak digunakan karena dalam penggunaannya memakan biaya rendah serta dengan waktu yang cepat dalam memperoleh suatu informasi dimanapun dan kapanpun ${ }^{[2]}$.

Pada sistem SMS dikenal pula istilah SMS gateway. SMS gateway merupakan sebuah sistem yang dipergunakan untuk memudahkan seseorang atau sebuah perusahaan mengirimkan pesan SMS yang sama dalam waktu yang bersamaan pada banyak orang ${ }^{[3]}$.

Dengan latar belakang tersebut, dalam tugas akhir ini diusulkan sebuah aplikasi penjadwalan agenda rapat yang memanfaatkan teknologi komunikasi handphone serta sebuah aplikasi penjadwalan yang diharapkan akan mempermudah proses pengelolaan rapat diatas dengan memanfaatkan fasilitas web dan SMS gateway. Berdasarkan penjelasan di atas, maka diputuskan untuk membangun sebuah aplikasi yang berjudul : "Sistem Informasi Agenda Rapat Berbasis SMS Gateway Menggunakan CodeIgniter dan MySQL Studi Kasus Politeknik TEDC Bandung"

\section{Landasan Teori}

\subsection{Sistem Informasi}

Sistem informasi adalah suatu sistem di dalam suatu organisasi pengolahan transaksi harian, mendukung operasi yang bersifat manajerial dan kegiatan strategis dari laporan-laporan yang diperlukan ${ }^{[4]}$.

\subsection{Manajemen Rapat}

Manajemen rapat adalah merencanakan, mengorganisasikan, memimpin, dan mengontrol rapat yang merupakan suatu kegiatan tatap muka resmi yang telah diagendakan yang dilakukan oleh dua orang atau lebih yang bertujuan untuk membahas suatu permasalahan, mencari jalan keluarnya dan mengambil keputusannya agar mencapai tujuan ${ }^{[2]}$.

\subsection{SMS (Short Message Service)}

SMS adalah kependekan dari Short Messages Services. Ini merupakan sebuah teknologi yang menyediakan pelayanan pengiriman dan penerimaan pesan antar mobile phone. SMS pertama kali dikenalkan di Eropa sekitar tahun
1992, yang pertama kali terintegrasi dalam GSM (Global System for Mobile, Communications) yang kemudian berkembang dalam CDMA dan TDMA ${ }^{[5]}$.

\subsection{SMS Gateway}

Secara umum SMS Gateway adalah sebuah sistem yang dipergunakan untuk memudahkan seseorang atau sebuah perusahaan mengirimkan pesan SMS yang sama dalam waktu yang bersamaan pada banyak orang. Selain itu, semakin berkembangnya fungsi SMS, SMS Gateway juga dapat dimanfaatkan untuk keperluan lain seperti melakukan polling, transaksi dengan sebuah sistem, pemantauan, dan sebagainya ${ }^{[3]}$.

\subsection{GAMMU}

Gammu adalah service yang disediakan untuk membangun aplikasi yang berbasis SMS gateway. Selain mudah, aplikasi SMS gateway dengan gammu adalah free. Ada dua mekanisme kerja dari gammu yaitu sebagai aplikasi dan sebagai deamon. Gammu sebagai aplikasi akan bekerja ketika perintah gammu dijalankan pada lingkungan shell beserta perintahnya disertakan sesuai fungsi yang diinginkan. Sedangkan sebagai deamon, gammu ditandai dengan dijalankannya perintah smsd pada shell. Pada prinsipnya cara kerja gammu yaitu menghubungkan modem/ponsel dengan PC. SMS yang diterima di modem / ponsel akan diambil oleh gammu untuk dipindahkan ke dalam database yang telah diatur sebelumnya. Cara kerja gammu dapat dilihat pada Gambar 1 berikut (Jumri, 2005).

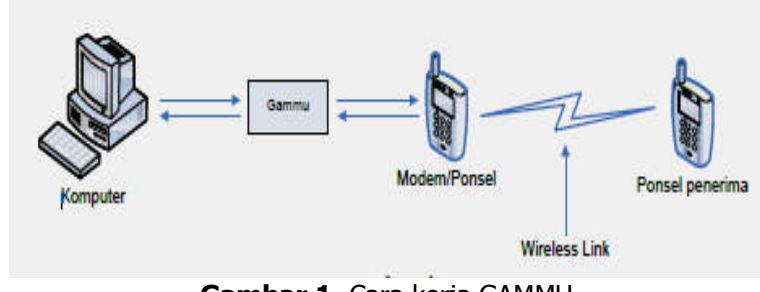

Gambar 1. Cara kerja GAMMU

\subsection{Codeigniter}

Code Igniter adalah sebuah framework PHP. Framework itu sendiri adalah suatu kerangka kerja yang berupa sekumpulan folder yang memuat file-file php yang menyediakan class libraries, helpers, plugins dan lainnya. Framework menyediakan konfigurasi dan teknik coding tertentu ${ }^{[4]}$.

\subsection{MySQL}

MySQL adalah sebuah perangkat lunak sistem manajemen basis data SQL (bahasa Inggris: database management system) atau DBMS yang multithread, multi-user, dengan sekitar 6 juta instalasi di seluruh dunia. MySQL AB membuat MySQL tersedia sebagai perangkat lunak gratis di bawah lisensi GNU General Public License (GPL), tetapi mereka juga menjual 
dibawah lisensi komersial untuk kasus-kasus dimana penggunaannya tidak cocok dengan penggunaan GPL

Unified Modelling Language (UML) adalah sebuah "bahasa" yg telah menjadi standar dalam industri untuk visualisasi, merancang dan mendok umentasikan sistem piranti lunak. UML menawarkan sebuah standar untuk merancang model sebuah sistem [6]

\subsection{UML}

Unified Modelling Language (UML) adalah suatu alat untuk memvisualisasikan dan mendokumentasikan hasil analisa dan desain yang berisi sintak dalam memodelkan sistem secara visual (Braun, et. al. 2001). Juga merupakan satu kumpulan konvensi pemodelan yang digunakan untuk menentukan atau menggambarkan sebuah sistem software yang terkait dengan objek [7].

A. Use Case Diagram

Use case diagram menggambarkan fungsionalitas yang diharapkan dari sebuah sistem. yang ditekankan adalah "apa" yang diperbuat sistem, dan bukan "bagaimana". Sebuah use case merepresentasikan sebuah interaksi antara aktor dengan sistem Seorang/sebuah aktor adalah sebuah entitas manusia atau mesin yang berinteraksi dengan sistem untuk melakukan pekerjaan-pekerjaan tertentu ${ }^{[8]}$.

\section{B. Activity Diagram}

Activity diagram menyediakan gambaran visual dari aliran aktifitas, baik dalam sistem, bisnis, alur kerja, atau proses lainnya. Diagram ini berfokus pada kegiatan yang dilakukan dan siapa (atau apa) yang bertanggung jawab atas kinerja dari kegiatan tersebut. Dalam banyak hal, diagram ini memainkan peran yang mirip dengan diagram alur, tetapi perbedaan utama antara mereka dan notasi flowchart adalah bahwa mereka mendukung perilaku secara paralel ${ }^{[8] \text {. }}$

\section{Class Diagram}

Class Diagram adalah sebuah spesifikasi yang jika diinstansiasi akan menghasilkan sebuah obyek dan merupakan inti dari pengembangan dan desain berorientasi obyek. Sebuah class diagram digunakan untuk menunjukkan keberadaan dari kelas dan hubungannya di dalam pandangan logic dari sebuah sistem. Sebuah kelas tunggal merepresentasikan sebuah sudut pandang dari struktur kelas dari sebuah sistem. Class menggambarkan keadaan (atribut/properti) suatu sistem, sekaligus menawarkan layanan untuk memanipulasi keadaan tersebut (metoda/fungsi) $[8]$.

\section{Pembahasan}

\subsection{Sistem yang sedang berjalan}

Pengolahan informasi agenda rapat yang sedang berjalan di Politeknik TEDC Bandung saat ini masih secara manual, yaitu dengan cara menyebarkan undangan kepada anggota rapat. Selain itu notula hasil rapat juga masih dicatat pada buku notula rapat.

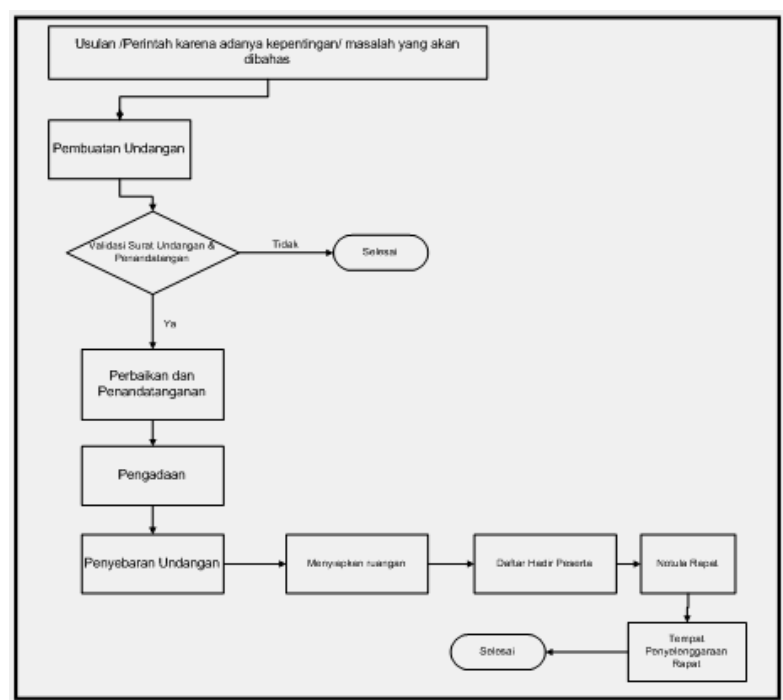

Gambar 2. Sistem yang sedang berjalan

\subsection{Sistem Yang Akan Dibangun}

Sistem informasi yang akan dikembangkan yaitu sistem informasi agenda rapat berbasis web menggunakan CodeIgniter dan MySQL, Serta akan ada penambahan yaitu pengiriman informasi tentang undangan rapat dan informasi lainya kepada staff, dosen atau orang yang berkepentingan menggunakan SMS Gateway sehingga lebih mengefisensikan waktu dalam pemberian informasi.

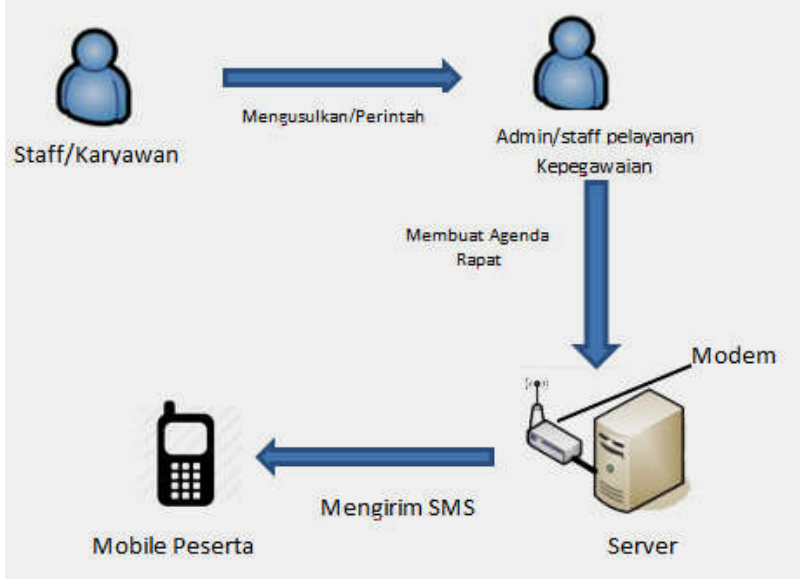

Gambar 3. Sistem yang akan dibangun 


\subsection{Use Case Diagram}

Untuk mengenal proses dari suatu sistem digunakan diagram use case. Dengan diagram use case diagram dapat diketahui proses yang terjadi pada sistem.

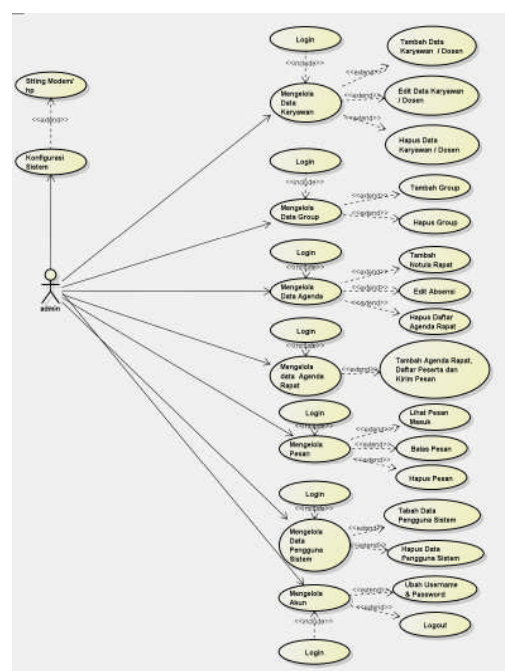

Gambar 4. Use case diagram

\subsection{Activity Diagram}

Merupakan Activity diagram yang digunakan untuk proses pada system.

1. Membuat Agenda Rapat, List Peserta dan mengirim Pesan

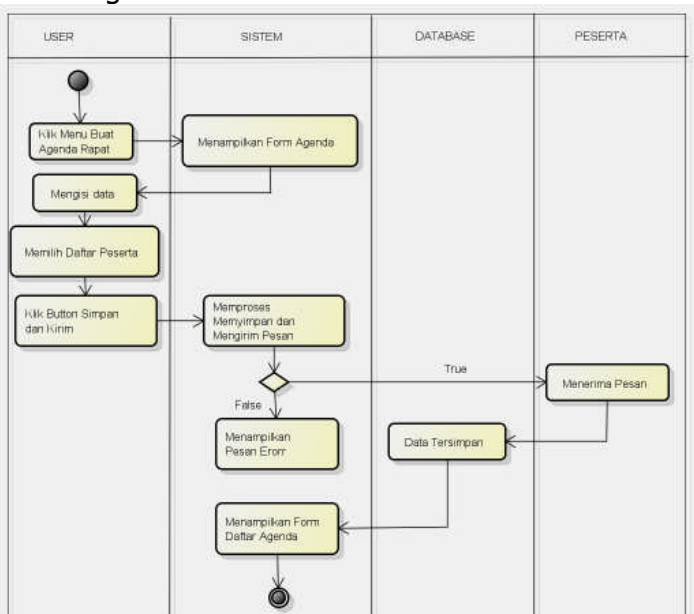

Gambar 5. Activity Diagram Membuat Agenda Rapat, List Peserta dan mengirim Pesan

2. Tambah Notula Rapat

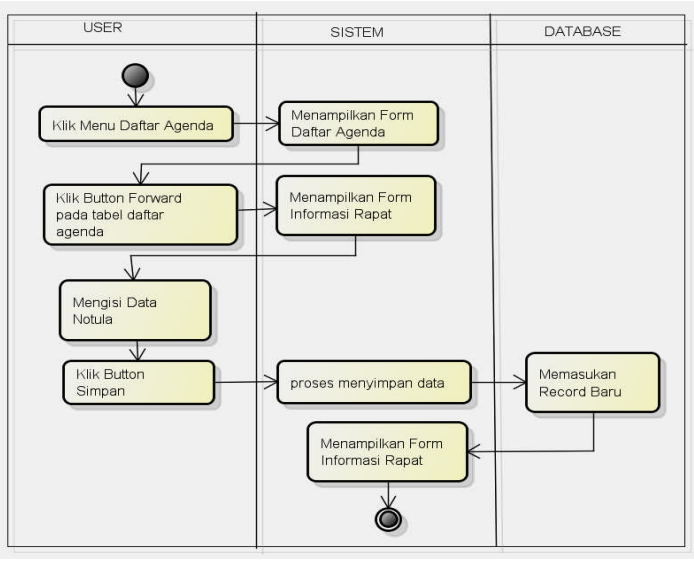

Gambar 6. Activity Diagram Tambah Notula Rapat

3. Edit Notula Rapat

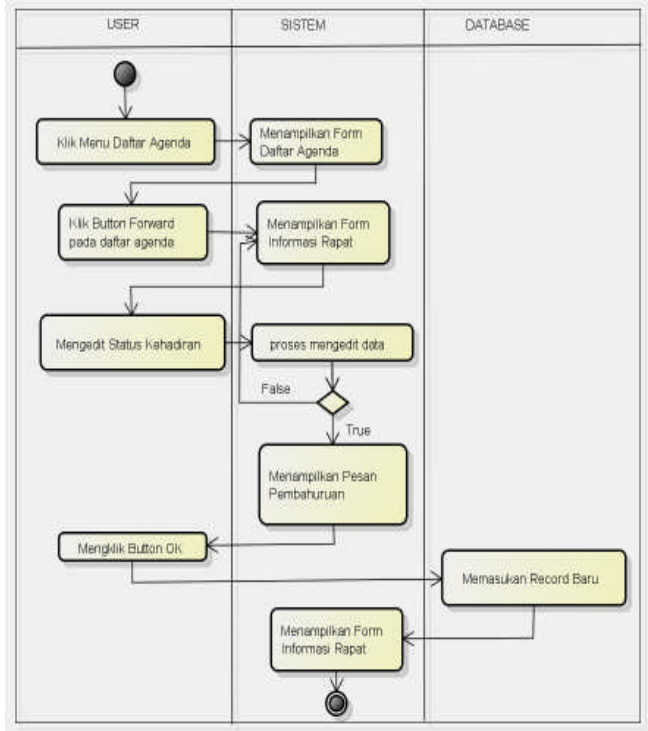

Gambar 7. Activity Diagram Edit Notula Rapat

4. Hapus Daftar Agenda

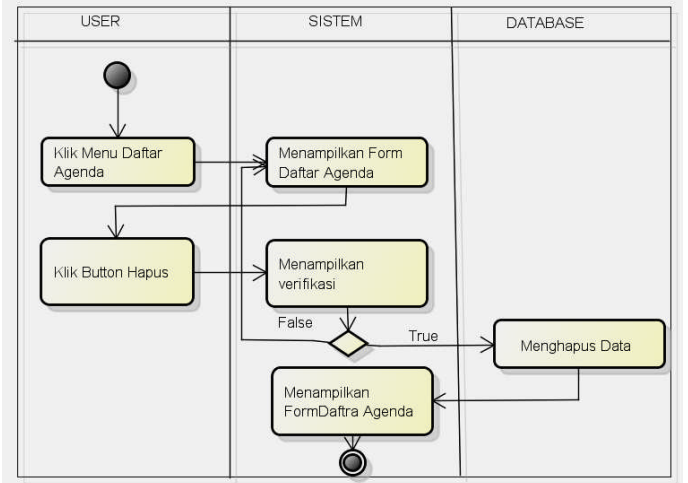

Gambar 8. Activity Diagram Hapus Notula Rapat 


\subsection{Entity Relationship Diagram}

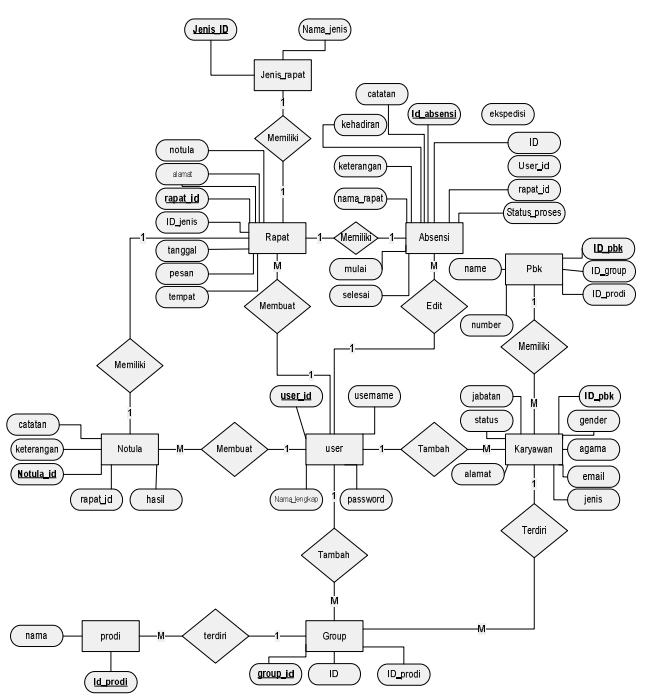

Gambar 9. ERD Perancangan Database

3.6 Tampilan Aplikasi

1. Tampilan Menu Login

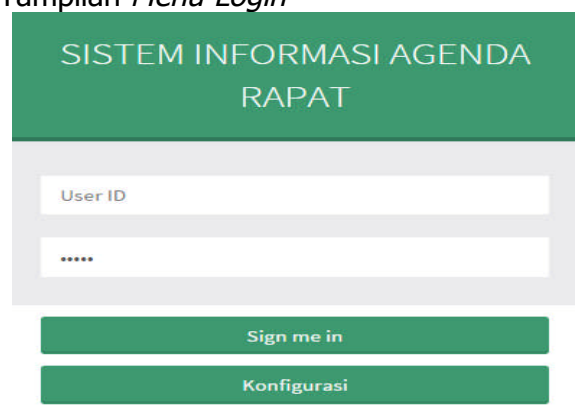

Gambar 10. Menu Login

Penjelasan :

a) Sebelum masuk ke menu utama aplikasi sistem informasi agenda rapat, user harus melewati menu login untuk dapat mengakses isi dari semua menu aplikasi

b) Menu login ini hanya untuk admin/user yang dapat mengelola aplikasi tersebut.

\section{Tampilan Main Menu}

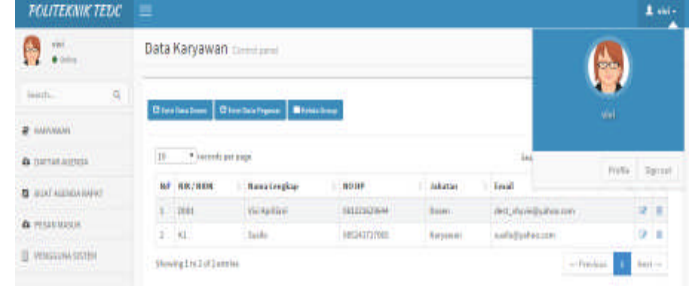

Gambar 11. Form Main Menu

\section{Tampilan Form Tambah Data Dosen}

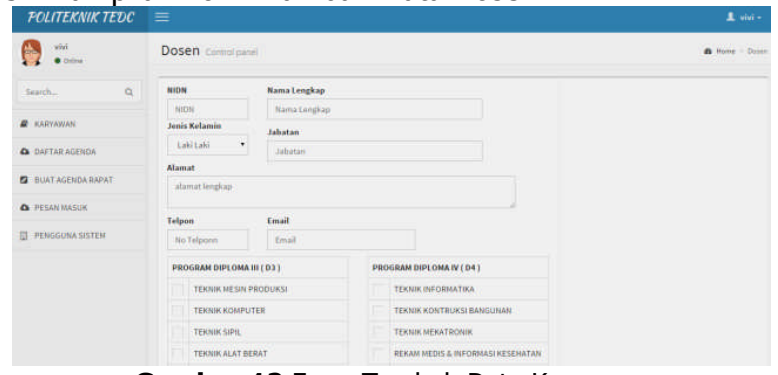

Gambar 12 Form Tambah Data Karyawan

Penjelasan :

a) Merupakan form penginputan data dosen yang muncul saat user memilih button entri data dosen pada Menu karyawan.

b) Daftar prodi merupakan data program studi yang di ambil oleh dosen dan nantinya merupakan data group.

4. Tampilan Form Tambah Data Karyawan

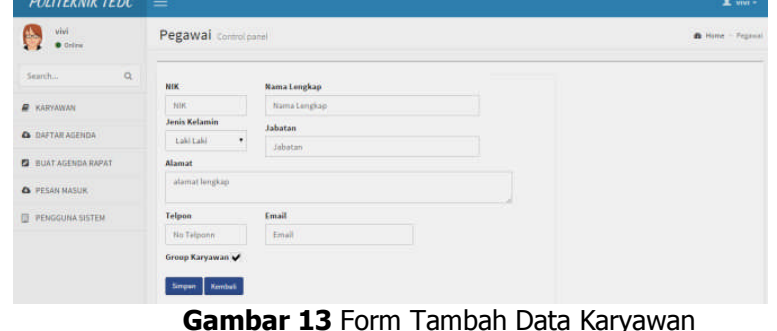

5. Tampilan Form Tambah Group

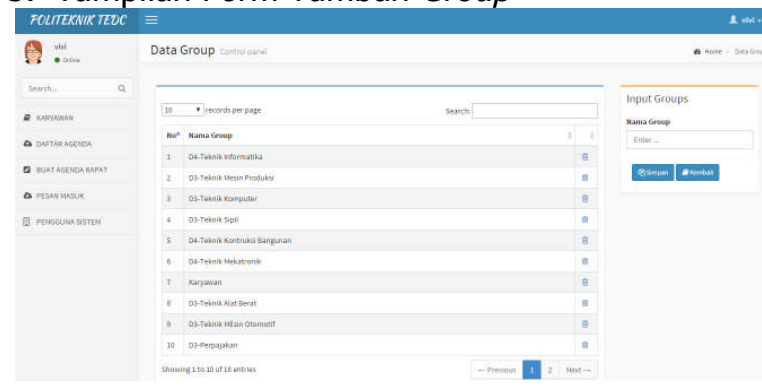

Gambar 14. Form Tambah Group

Penjelasan :

User menambahkan group untuk mempermudah dalam mengfilter data perprodi apabila user ingin membuat agenda rapat per-prodi saja.

6. Tampilan Form Tambah Agenda, Peserta dan Kirim Pesan 


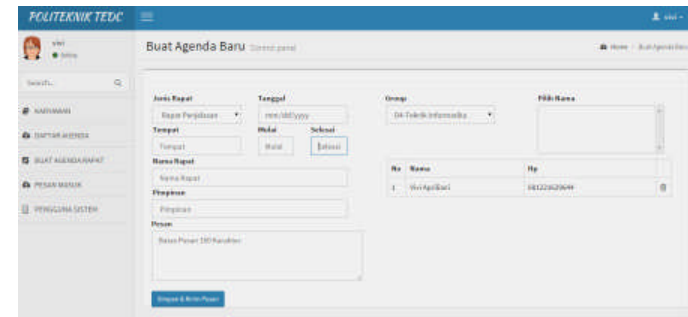

Gambar 15. Form Tambah Agenda, Peserta dan Kirim Pesan

Penjelasan :

a) User menambahkan agenda rapat pada menu tambah agenda rapat.

b) User memilih peserta yang akan dikirimi pesan via SMS menggunakan SMS Gateway dengan memilih prodi.

7. Tampilan informasi Rapat

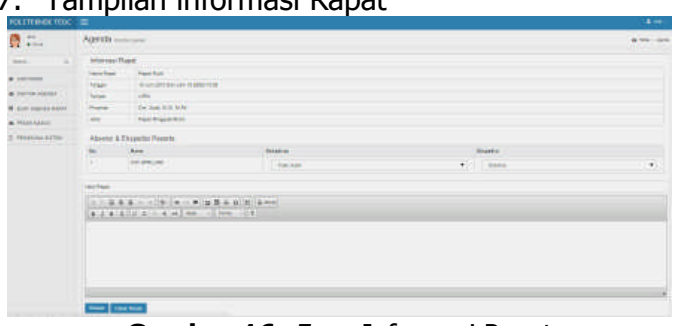

Gambar 16. Form Informasi Rapat

Penjelasan :

a) User mengklik menu notula pada form daftar agenda untuk masuk ke form informasi rapat.

b) Form informasi rapat merupakan form notula dan absensi peserta rapat

8. Tampilan Cetak Notula Rapat

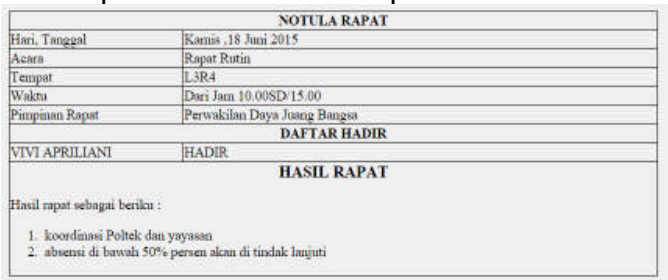

Gambar 17. Cetak Notula Rapat

\section{Tampilan Membuat Surat}

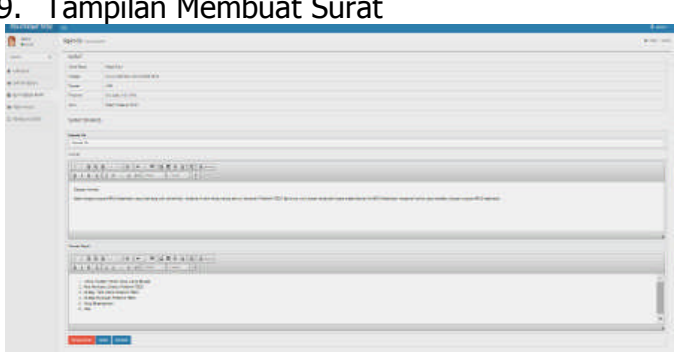

Gambar 18. Form Membuat Surat
Penjelasan :

a) User mengklik button surat pada menu daftra agenda.

b) Form surat ini merupakan form untuk membuat surat rapat apabila diperlukan.

10. Tampilan Pesan Masuk

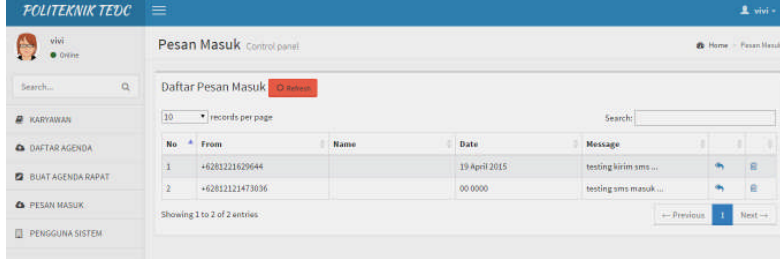

Gambar 19. Form Pesan Masuk

Penjelasan :

Form pesan masuk untuk melihat pesan masuk yang berasal dari pegawai Politeknik TEDC Bandung

11. Tampilan Balas Pesan Masuk

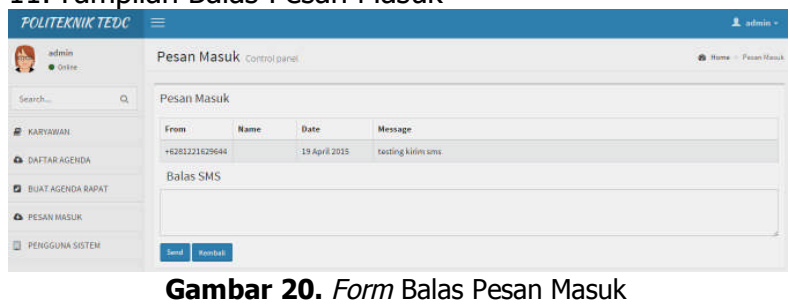

\section{Tampilan Kelola User}

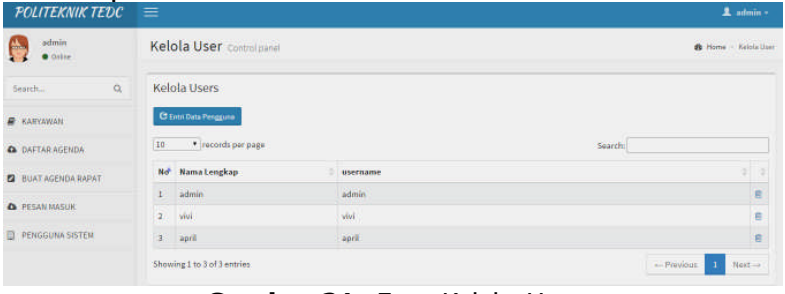

Gambar 21. Form Kelola User

Penjelasan :

User dapat menambahkan pengguna sistem yang dapat mengakses aplikasi ini.

\section{Kesimpulan dan Saran}

\subsection{Kesimpulan}

Berdasaran hasil penelitian dan uji coba yang telah dilakukan, dapat diambil kesimpulan mengenai Sistem Informasi Agenda Rapat di Politeknik TEDC Bandung , diantaranya :

1. Dengan dibuatnya sistem informasi agenda rapat di Politeknik TEDC Bandung ini dapat membantu bagian kepegawaian dalam penginputan data karyawan dan juga data agenda rapat sehingga lebih tertata rapi dan lebih efektif. 
2. Sistem informasi agenda rapat di Politeknik TEDC Bandung yang dibuat ini dapat membantu bagian kepegawaian dalam pembuatan surat atau laporan agenda rapat.

3. Dengan adanya sistem informasi agenda rapat di Politeknik TEDC Bandung berbasis teknologi SMS Gateway ini, penyebaran informasi rapat atau informasi lainya dapat langsung di terima oleh dosen atau karyawan yang dikirim melalui via sms sehingga informasi yang didapatkan tepat waktu dan merupakan informasi yang akurat.

\subsection{Saran}

Adapun saran-saran yang dapat disampaikan penulis bagi pengembang aplikasi ini yaitu:

1. Sistem informasi agenda rapat ini bisa dikembangkan lagi dari segi tampilan.

2. Pada aplikasi sms gateway dapat mengecek pulsa otomatis tanpa harus membuka cmd

3. Dalam pencetakan undangan rapat, tanda tangan ka.sub kepegawaian bisa ditampilkan secara otomatis pada lembar surat undangan.

\section{Daftar Pustaka}

[1]A. A. Pamungkas, "Literatur Review Manajemen Rapat Efektif Bagi Perusahaan," pp. 112, 2015.

[2]Y. Wiharto, "Sistem Informasi Akademik," vol. 1, no. 1, pp. 1-28, 2011.

[3]Y. A. Wijaya and I. A. Faisal, "Sistem Informasi Absensi Siswa Berbasis SMS Gateway Guna Mempercepat Penyapaian Data Absensi Siswa Di MADRASAH ALIYAH NEGERI 2 CIREBON," vol. 1, no. 2, pp. 15-24, 2012.

[4]Jogianto, “Konsep Dasar Sistem Informasi," pp. 9-22, 2001.

[5]H. Murti and H. Listiyono, "Aplikasi SMS Gateway," vol. XIV, no. 1, pp. 30-34, 2009.

[6]A. Solichin and S. Kom, "Pemrograman Web dengan PHP dan MySQL," universitas Budi Luhur, Jakarta, pp. 1-122, 2005.

[7]Haviluddin, "Memahami Penggunaan UML (Unified Modelling Language)," vol. 6, no. 1, pp. 1-15, 2011.

[8]A. P. Utomo, "Analisa Dan Perancangan Sistem Informasi Parkir di UNIVERSITAS MURIA KUDUS," SIMETRIS, vol. 3, no. 1, pp. 17-24, 2013. 